\title{
A QUESTÃO DE GÊNERO COMO VULNERABILIDADE DA MULHER: DA CONVENÇÃO DE BELÉM DO PARÁ À LEI MARIA DA PENHA
}

\author{
THE GENDER ISSUES AS A VULNERABILITY OF WOMAN: FROM THE BELÉM \\ DO PARÁ CONVENTION TO THE MARIA DA PENHA LAW
}

\author{
${ }^{1}$ Bárbara Helena Simões \\ ${ }^{2}$ Cicero Krupp da Luz
}

\section{RESUMO}

A diferença entre gêneros e a suposta superioridade masculina cria uma posição de vulnerabilidade para mulheres. A OEA adotou a Convenção Interamericana para Prevenir, Punir e Erradicar a Violência contra a Mulher, ratificada pelo Brasil em 1995. Após responsabilização pela Comissão Interamericana, no caso "Maria da Penha", em 2006, o Brasil publicou a Lei 11.340, para proteção das mulheres. Este trabalho reflete sobre a relação entre a violência de gênero e a atuação do direito internacional na promoção e proteção dos direitos das mulheres, analisando a Convenção de Belém do Pará e a atuação da CIDH no caso em análise.

Palavras-chave: Comissão interamericana de direitos humanos, Convenção de belém do pará, Lei maria da penha, Violência de gênero

\begin{abstract}
The difference between genders and the supposed male superiority create a vulnerable environment for women. The OAS adopted the Inter-American Convention on the Prevention, Punishment and Eradication of Violence against Women, ratified by Brazil in 1995. After hold accountable the Inter-American Commission in the case "Maria da Penha" in 2006, Brazil enacted Law 11.340, for protection of the women. This work reflects the relationship between gender violence and the role of international law in promoting and protecting women's rights, analyzing the Belém do Pará Convention and the IACHR's action in this case.
\end{abstract}

Keywords: Inter-american commission on human rights, Belém do pará convention, Maria da penha law, Gender violence

\footnotetext{
${ }^{1}$ Mestranda em Direito pela Faculdade de Direito do Sul de Minas - FDSM, Minas Gerais (Brasil). Professora de Direito pela Faculdade de Direito do Sul de Minas, FDSM, Minas Gerais (Brasil).

E-mail: barbarahelenasimoes@gmail.com

${ }^{2}$ Doutor em Relações Internacionaispela Universidade de São Paulo - USP, São Paulo (Brasil). Professor de Direito pela Faculdade de Direito do Sul de Minas, FDSM, Minas Gerais (Brasil). E-mail: ciceroluz@gmail.com
} 


\section{Introdução}

A diferença entre homens e mulheres tem sido alvo de discussão por todo o mundo, principlamente em razão da posição de vulnerabilidade que essa dicotomia cria para as mulheres. Nenhuma sociedade trata de maneira igual seus homens e mulheres. Conforme estabelece o Relatório de Desenvolvimento Humano de 2014, editado pelo Programa das Nações Unidas para o Desenvolvimento (PNUD,2014), as mulheres se encontram no grupo de pessoas vulneráveis, pelo simples fato de serem mulheres.

Nesse sentido, em razão da ideologia patriacarlista que nos cerca, as mulheres são relegadas a cumprir papel de cidadãs de segunda classe não possuindo os mesmos direitos e oportunidades que os cidadãos do sexo oposto, e a eles são subjulgadas. Isto faz com que a violência contra elas esteja sempre presente. Esse tipo de violência, baseada na questão de gênero, interfere significativamente no exercício dos direitos de cidadania e na qualidade de vida de mulheres, limitando seu pleno desenvolvimento enquanto sujeitos humanos constituintes da sociedade.

A violência de gênero afeta, igualmente, o pleno desenvolvimento da sociedade em sua diversidade, fator de fácil identificação por uma análise dos índices de Desigualdade de Gênero e de Desenvolvimento Humano por Gênero calculado pela PNUD. No Brasil, por exemplo, em 2013, as mulheres ocupavam apenas 9,6\% dos assentos no parlamento, sendo que sua participação na força de trabalho era equivalente a 59,5\% contra 80,9\% dos homens (PNUD, 2014).

Todavia, na atualidade, frente às noções de constitucionalismo e cidadania, a manutenção da ideologia patriarcalista e a reafirmação do ilusório "direito natural" (AGENDE, 2004) de diferenciação dos papéis sociais com base em diferenças de gênero não encontram mais suporte. Nesse sentido, subjulgar mulheres e submetê-las a agressões de qualquer espécie não é prerrogativa conferida naturalmente aos homens. Pelo contrário, esse comportamento masculino, muitas vezes referendado até mesmo pelo Estado ${ }^{1}$

\footnotetext{
${ }^{1}$ Um exemplo emblemático foram as ameaças proferidas pelo Deputado Federal Jair Bolsonaro à sua colega, deputada Maria do Rosário. Em sessão da câmara o deputado disse à colega que não a estupraria pois ela era feia. Disponível em: $<$ http://www.revistaforum.com.br/blog/2014/12/nao-estupro-voce-porque-nao-merece-dizbolsonaro-maria-rosario/> Acesso em 13/09/2015.
} 
reflete uma incapacidade de reconhecer que os direitos humanos também são direitos das mulheres e que, a violência contra elas é algo inadmissível e intolerável num Estado Constitucional Democrático de Direto.

Com o intuito de proteger e promover o empoderamento desse grupo, a Organização dos Estados Americanos adotou em 1994 a Convenção Interamericana para Prevenir, Punir e Erradicar a Violência contra a Mulher, também denominada de Convenção de Belém do Pará, a qual foi ratificada pelo Brasil em 27 de novembro de 1995. Dentre muitos atos e propostas, a Convenção define o que se entende por violência contra o sexo feminino. ${ }^{2}$

Entretanto, o Estado Brasileiro se manteve inerte no que tange à criação de leis e políticas públicas para a proteção das mulheres. Essa inércia fez com que, em 2001, após o emblemático caso "Maria da Pena", a Comissão Interamericana de Direitos Humanos, em seu informe $n^{\circ} 54$, tendo como fundamento a Convenção de Belém do Pará, responsabilizasse o Brasil por negligência, omissão e tolerância em relação à violência doméstica contra as mulheres, estabelecendo inúmeras recomendações ao país. Como consequência, a Lei 11.340/2006, popularmente conhecida como Lei Maria da Penha, foi aprovada, estabelecendo um novo rol de direitos para a proteção contra a violência doméstica e familiar sofrida pelas mulheres.

Diante de todo o exposto, o principal problema é: a questão de gênero tem levado à vulnerabilidade da mulher? De que forma o direito internacional contribui para a minimização desse problema?

Nessa perspectiva, a proposta procura refletir sobre a relação entre a violência contra a mulher e a atuação do direito internacional na promoção de direitos e na proteção das mulheres. O argumento central está em torno da análise da Convenção Interamericana para prevenir, punir e erradicar a violência contra a mulher e explorando o itinerário da atuação da Comissão Interamericana de Direitos Humanos no caso Maria da Penha. O método utilizado para atingir os objetivos estabelecidos neste estudo será o analítico dedutivo, buscando esclarecer conceitos, elucidar proposições, partindo de uma ampla pesquisa bibliografia sobre

\footnotetext{
2 A proteção Internacional dos direitos humanos das mulheres é vasta. Para citar mais alguns exemplos, temos a Convenção Sobre Todas as Formas de Discriminação contra a Mulher de 1979 e a Declaração sobre a Eliminação da Violência contra a Mulher, adotada em 1993 pela ONU.
} 
o tema. Para a concretização das intenções do método analítico, os procedimentos usados deverão ser o da pesquisa bibliográfica por meio de textos legais, doutrinários, livros e artigos relacionados à temática.

\section{A Convenção Interamericana para prevenir, punir e erradicar a violência contra a mulher}

A Convenção de Belém do Pará, como também é conhecida a Convenção Interamericana para prevenir, punir e erradicar a violência contra as mulheres, foi adotada pela Assembleia Geral da Organização dos Estados Americanos (OEA) no dia 09 de junho de 1994, vindo a ser aprovada pelo Brasil, apenas em $1^{\circ}$ de setembro de 1995 , mediante o Decreto Legislativo n. ${ }^{\circ}$ 107, e ratificada pelo país em 27 de novembro de 1995. Ao afirmar que "a violência contra a mulher constitui violação dos direitos humanos e liberdades fundamentais e limita total ou parcialmente a observância, gozo e exercício de tais direitos e liberdades" (COMISSÃO INTERAMERICANA DE DIREITOS HUMANOS, 1994), a Convenção constitui importante ferramenta de promoção da emancipação das mulheres. Principalmente porque evidencia que "a eliminação da violência contra a mulher é condição indispensável para seu desenvolvimento individual e sua plena e igualitária participação em todas as esferas de vida" (COMISSÃO INTERAMERICANA DE DIREITOS HUMANOS, 1994).

Assim, a Convenção de Belém do Pará conceitua claramente o que se entende por violência contra a mulher: "qualquer ato ou conduta baseada no gênero, que cause morte, dano ou sofrimento físico, sexual ou psicológico à mulher, tanto na esfera pública como na esfera privada" (COMISSÃO INTERAMERICANA DE DIREITOS HUMANOS, 1994). Nesse mesmo sentido, a Convenção determina que a violência contra a mulher compreende tanto a violência física, quanto a sexual e psicológica, bem como aquelas que ocorrem seja no âmbito da família ou da unidade doméstica, na comunidade e cometida por qualquer pessoa e as perpetradas ou toleradas pelo Estado ou seus agentes, onde quer que ocorram. Determina, 
portanto, que "toda mulher tem direito a ser livre de violência, tanto na esfera pública quanto na privada” (COMISSÃO INTERAMERICANA DE DIREITOS HUMANOS, 1994).

Em seu artigo $4^{\circ}$, a Convenção prevê ainda direitos das mulheres, entre eles os direitos a não ser submetida à tortura; a que se respeite a dignidade inerente à sua pessoa e a que se proteja sua família; a igual proteção perante a lei e da lei; a recurso simples e rápido perante tribunal competente que a proteja contra atos que violem seus direitos; a livre associação; à liberdade de professar a própria religião e as próprias crenças, de acordo com a lei; e, inclusive, a ter igualdade de acesso às funções públicas de seu país e a participar nos assuntos públicos, principalmente na tomada de decisões.

São elencados também, os deveres assumidos pelos Estados ao ratificar a Convenção. O primeiro deles é a necessidade do Estado de agir com o devido zelo para prevenir, investigar e punir a violência contra a mulher, levando em conta a situação da mulher vulnerável à violência por sua raça, origem étnica ou condição de migrante, de refugiada ou de deslocada e também considerando como sujeita à violência a gestante, deficiente, menor, idosa ou em situação socioeconômica desfavorável, afetada por situações de conflito armado ou de privação da liberdade.

Ademais, é dever do Estado, segundo a Convenção, incorporar na sua legislação interna normas penais, civis, administrativas e de outra natureza, que sejam necessárias para prevenir, punir e erradicar a violência contra a mulher, bem como adotar as medidas administrativas adequadas que forem aplicáveis. É de extrema relevância que o Estado tome todas as medidas adequadas, inclusive legislativas, para modificar ou abolir leis e regulamentos vigentes ou modificar práticas jurídicas ou consuetudinárias que respaldem a persistência e a tolerância da violência contra a mulher. E, ainda, estabelecer procedimentos jurídicos justos e eficazes para a mulher sujeitada à violência, inclusive, entre outros, medidas de proteção, juízo oportuno e efetivo acesso a tais processos.

Ao ratificar a Convenção, os Estados Partes devem adotar, progressivamente, medidas específicas, inclusive programas destinados a promover o conhecimento e a observância do direito da mulher a uma vida livre de violência e o direito da mulher a que se respeitem e protejam seus direitos humanos; modificar os padrões sociais e culturais de conduta de homens e mulheres, inclusive a formulação de programas formais e não formais adequados a 
todos os níveis do processo educacional, a fim de combater preconceitos e costumes e todas as outras práticas baseadas na premissa da inferioridade ou superioridade de qualquer dos gêneros ou nos papéis estereotipados para o homem e a mulher, que legitimem ou exacerbem a violência contra a mulher.

A Convenção estabelece ainda que para a adoção das medidas acima previstas, os Estados que a ratificarem deverão levar especialmente em consideração a situação da mulher vulnerável a violência por sua raça, origem étnica ou condição de migrante, de refugiada ou de deslocada, entre outros motivos. Também deverá ser considerada sujeita à violência a gestante, deficiente, menor, idosa ou em situação socioeconômica desfavorável, afetada por situações de conflito armado ou de privação de liberdade.

Também foram estabelecidos e reafirmados os mecanismos interamericanos de proteção de direitos humanos. O mais importante e eficaz destes mecanismos é a possibilidade de qualquer pessoa, ou qualquer entidade não governamental juridicamente reconhecida em um ou mais Estados membro da OEA, apresentar à Comissão Interamericana de Direitos Humanos petições referentes a denúncias ou queixas de violações do artigo 7 da Convenção por um Estado Parte. Assim, cabe a Comissão considerar tais petições de acordo com normas e procedimentos estabelecidos na Convenção Americana sobre Direitos Humanos e no Estatuto da Comissão Interamericana de Direitos Humanos. Esse mecanismo de proteção foi acionando em 1998 contra o Brasil, dando origem ao paradigmático caso número 12.051- Maria da Penha Maia Fernandes x Brasil.

\section{Caso Maria da Penha e a criação da Lei 11.340/2006}

Em 20 de Agosto de 1998, a Comissão Interamericana de Direitos Humanos recebeu uma denúncia apresentada pela senhora Maria da Pena Maia Fernandes, representada e com o apoio do Centro pela Justiça e pelo Direito Internacional (CEJIL) e pelo Comitê LatinoAmericano de defesa dos Direitos da Mulher (CLADEM) (COMISSÃO INTERMERICANA DE DIREITOS HUMANOS, 2001). A denúncia alegava a tolerância da República Federativa do Brasil para com a violência cometida por Marco Antônio Heredia Viveiros em seu 
domicílio na cidade de Fortaleza, Estado do Ceará, contra a sua então esposa Maria da Penha Maia Fernandes durante os anos de convivência matrimonial, que culminou numa tentativa de homicídio e em novas agressões em maio e junho de 1983. Em decorrência dessas agressões, a peticionária sofreu uma série de enfermidades, dentre elas a paraplegia irreversível. A tolerância do Estado teria se dado vez que, apesar das inúmeras denúncias, ele não havia efetivamente tomado, por mais de 15 anos, as medidas necessárias para processar e punir o agressor. $\mathrm{O}$ caso em análise violou os artigos 1, 8, 24 e 25 da Convenção Americana, bem como os artigos 4, alíneas "a" a "g”, 5 e 7 da Convenção de Belém do Pará.

Recebida a petição, em 19 de outubro de 1998, a Comissão Interamericana transmitiu a petição ao Estado Brasileiro e solicitou-lhe informações a respeito da mesma (COMISSÃO INTERMERICANA DE DIREITOS HUMANOS, 2001). Diante da falta de resposta do Estado, em 02 de gosto de 1999, os peticionários solicitaram a aplicação do artigo 42 do Regulamento da Comissão com o propósito de que se presumissem serem verdadeiros os fatos relatados na denúncia, uma vez que haviam decorrido mais de 250 dias desde a transmissão da petição ao Brasil e o país não havia apresentado observações ao caso.

Em 04 de agosto de 1999, a Comissão reiterou ao Estado Brasileiro sua solicitação de envio das informações que considerasse pertinentes, advertindo-o da possibilidade de aplicação do artigo 42. Já em 07 de Agosto de 2000, a Comissão se colocou à disposição das partes por 30 dias para dar início a um processo de solução amistosa de acordo, o que entendeu não ser viável, já que nenhuma das partes se manifestou.

Cumpridos todos os requisitos de admissibilidade da petição, como o atraso injustificado na decisão dos recursos interno, a Comissão concluiu que a República Federativa do Brasil era responsável pela violação dos direitos às garantias judiciais e à proteção judicial, previstos nos artigos 8 e 25 da Convenção Americana, bem como os diretos e o cumprimento de seus deveres previstos no artigo $7^{\circ}$ da Convenção de Belém do Pará, por seus próprios atos omissivos e tolerantes da violação infligida. Ainda foi concluído que as violações acima expostas seguem um padrão discriminatório com respeito à tolerância da violência doméstica contra mulheres no Brasil por ineficácia de ação judicial.

Nesse sentido, em 04 de abril de 2001, 18 anos após a prática dos crimes, e ante a ausência de resposta do Estado Brasileiro, a Comissão emitiu parecer no qual o país foi 
acusado por negligência e omissão em relação à violência doméstica. Para a CIDH, esta violação constituída um padrão de discriminação evidenciado pela aceitação da convivência contra as mulheres no Brasil através da ineficácia do Judiciário (SANTOS, 2010).

Ao tornar público o relatório 54/01 e incluí-lo no Relatório Anual à Assembleia Geral da OEA, a Comissão reiterou as seguintes recomendações: que o Brasil completasse rápida e efetivamente o processamento penal do responsável pela agressão e tentativa de homicídio à Senhora Maria da Penha Maia Fernandes; que o país procedesse a uma investigação séria, imparcial e exaustiva, a fim de determinar a responsabilidade pelas irregularidades e atrasos injustificados que impediram o processamento rápido e efetivo do responsável, bem como tomar as medidas administrativas, legislativas e judiciárias correspondentes; que fossem adotadas medidas necessárias para que o Estado assegure à vítima adequada reparação simbólica e material pelas violações constatadas; mas, principalmente, que o Braisl prosseguisse e intensificasse o processo de reforma que evite a tolerância estatal e o tratamento discriminatório com respeito à violência doméstica contra mulheres no Brasil.

Em 31 de outubro de 2002, após 19 anos, Marco Antônio Heredia Viveiros foi preso, no Estado da Paraíba, o que colocou fim ao ciclo de impunidades. As demais recomendações propostas pela Comissão Interamericana foram objeto de um termo de compromisso firmado entre as entidades peticionarias e o Estado Brasileiro. Já em 24 de novembro de 2003, o país adotou a Lei 10.778 que determina a notificação compulsória pelos serviço de saúde públicos ou privados de casos que envolvam violência contra a mulher (PIOVESAN, 2011).

Em 2003, foi criada a Secretaria Especial de Políticas para Mulheres (SPM), com status Ministerial, que desde sua criar tem desempenhado relevante papel na formulação e promoção de políticas públicas para as mulheres, tendo como uma de suas prioridades a violência doméstica. A criação dessa Secretaria permitiu a aliança entre governo e organizações não-governamentais feministas (SANTOS, 2010).

No início de 2004, o Decreto 5.030 instituiu um Grupo de Trabalho Interministerial, que, com a participação da sociedade civil e do Governo, elaborou uma proposta de medida legislativa e outros instrumentos capazes de coibir a violência doméstica contra a mulher. Referido grupo elaborou uma proposta que foi encaminhada ao Congresso Nacional no final do Ano de 2004, sendo que, em 07 de agosto de 2006, foi promulgada a Lei 11.340, apelidada 
"Lei Maria da Penha", a qual entrou em vigor em 22 de setembro de 2006 e criou novos tipos penais, arranjos institucionais e políticas públicas no campo dos direitos da mulher (SANTOS, 2010).

A Lei teve como principal objetivo a criação de mecanismos para coibir a violência doméstica e familiar contra a mulher, definindo-a como uma violação dos direitos humanos e uma forma de violência baseada no gênero (SANTOS, 2010). Foram inúmeras as inovações introduzidas pela Lei Maria da Penha, e de acordo com Piovesan e Pimentel (2011), podemos destacar sete delas, quais sejam: a mudança de paradigma no enfrentamento da violência contra a mulher; a incorporação da perspectiva de gênero para tratar da violência contra a mulher; a incorporação da ótica preventiva, integrada e multidisciplinar; o fortalecimento da ótica repressiva; a harmonização com a Convenção Interamericana para prevenir, punir e erradicar a Violência contra a mulher; a consolidação de um conceito de família e visibilidade ao direito livre à orientação sexual; e o estímulo à criação de bancos de dados e estatísticas.

A Lei Maria da Penha ainda fez com que conflitos que envolvam violência contra a mulher não possam ser considerados de "menor potencial ofensivo", pelo contrário, em razão da ausência de estruturas e instrumentos adequados para tratar a violência contra a mulher, a Lei 11.340/06 afastou a aplicabilidade da lei 9.099/95 e, consequentemente, de suas medidas despenalizadoras (PIOVESAN, 2011), e instituindo a criação dos Juizados de Violência Doméstica e Familiar contra a Mulher, a serem implantados pelos tribunais de cada Estado. Além disso, a lei ainda trouxe o aumento da pena de detenção de seis meses a um ano para um mínimo de três meses.

Entretanto, surgiram várias controvérsias no âmbito de aplicar da Lei, vez que alguns magistrados e juristas entenderam que a mesma fere o princípio constitucional da igualdade entre homens e mulheres. Além disso, alguns magistrados continuaram a atribuir aos Juizados Especiais Criminais a competência para casos de violência doméstica, independentemente do tipo de lesão e da pena (SANTOS, 2010). Mesmo o Tribunal Superior de Justiça diverge sobre a natureza da ação penal nos casos de lesão corporal de natureza leve. Há, portanto, discussão sobre o alcance do artigo 41 da Lei que proíbe a aplicar da Lei 9.099/95 aos crimes de violência doméstica e familiar contra a mulher. 
Mas é certo que a promulgação da Lei Maria da Penha veio atender inclusive, à necessidade prevista em nossa Constituição da existência de leis diferenciadas para desigualar as desigualdades físicas e materiais existentes no Brasil. Ou seja, "a Constituição prevê discriminações positivas para através de um tratamento, desigual, buscar igualar aquilo que sempre foi desigual" (STRECK, 2011). Portanto, como bem colocam Piovesan e Pimentel (2011), ao enfrentar a violência que de forma desproporcional acomete tantas mulheres, a lei é instrumento de concretização da igualdade material entre homens e mulheres, sendo que “inconstitucional não é a Lei Maria da Penha, mas a ausência dela”.

A Campanha da Lei Maria da Penha foi responsável, principalmente, pela substituir da figura da mulher passiva e vitimizada pela figura da mulher encarnada pela própria Maria da Penha: sobrevivente de agressões rotineiras e vitoriosa ao fazer valer direitos violados, exigindo a reparar dos danos sofridos do Estado. Essa condição foi muito bem representada pelo slogan "Direito das Mulheres a uma Vida Sem Violência” (MACIEL, 2011). A partir desse paradigma, a utilização política dos instrumentos legais de proteção dos direitos humanos passou a ser utilizada tanto para legitimar juridicamente demandas e casos específicos nas cortes internacionais como para pressionar elites políticas nacionais.

A Lei foi capaz de promover o reconhecimento formal da vulnerabilidade da mulher nas relações domésticas, familiares e afetivas, bem como instituiu a força simbólica da pena na redefinição jurídica da violência como ato lesivo a valores e sentimentos coletivos, deslocando definitivamente o problema da esfera da vida privada para a esfera pública. O quadro interpretativo da violência de gênero como violação dos direitos humanos foi decisivo para transformar o direito em recurso político e simbólico, sendo que a tônica sexista foi substituída pela noção de direitos humanos, convertido conflitos privados em problema público a ser solucionado pela intervenção do aparato Estatal.

Com a aprovação da Lei 11.340/06 o Brasil passou a ser o $18^{\circ}$ país na América Latina e Caribe a ter uma legislação específica para o enfrentamento da violência doméstica e familiar (PASINATO, 2010). A legislação brasileira, diferentemente das demais, volta-se exclusivamente para a proteção dos direitos das mulheres, restringindo a proteção aos casos de violência que ocorrem em ambiente doméstico, nas relações familiares ou em relações íntimas de afeto. A Lei ainda estende esta proteção a qualquer mulher que tenha sido vítima 
de violência doméstica e familiar, independente de classe, raça, etnia, orientação sexual, renda, cultura, nível educacional, idade e religião.

A aprovação desta lei representou um marco no extenso processo histórico de reconhecimento da violência contra as mulheres como um problema social no Brasil, resultado de um processo que ganhou força a partir dos anos 1970, com intensa participação dos movimentos feministas que lutaram pela conquista da cidadania para todos clamando, principalmente, o respeito pelas diferenças de gênero (PASINATO, 2010). O texto legislativo engloba tanto as ideias feministas e as lutas pela conquista dos direitos para as mulheres, bem como a preocupação de uma abordagem para o enfrentamento à violência contra as mulheres, trazendo três tipos de medidas de enfrentamento, sendo elas, o combate, a proteção e a prevenção.

Todavia, o desafio maior na atualidade é o da implementação da lei, um dos principais objetivos do Pacto Nacional de Enfrentamento contra a Mulher, estabelecido pelo Governo Federal em 2007 (SANTOS, 2010). Ainda em 2007 foi criado o Observatório Nacional de Implementação e Aplicação da Lei Maria da Penha para produzir, analisar e divulgar informações sobre a aplicação da lei pelos órgãos públicos, financiado pela Secretaria Especial de Políticas para Mulher (MACIEL, 2011). Além do governo, as organizações não-governamentais feministas também têm dedicado esforços no monitoramento e implementação da Lei, pela promoção de conferências, como o "Balanço Nacional de Implementação da Lei Maria da Penha" promovido pelo Centro Feminista de Estudos em 2008.

\section{Considerações Finais}

Como se pode perceber, em razão da ideologia patriacarlista que nos cerca, as mulheres são relegadas a cumprir papel de cidadãs de segunda classe, o que faz com que a violência contra elas esteja sempre presente. Esse tipo de violência, pautada única e exclusivamente na questão de gênero, interfere significativamente no exercício dos direitos de 
cidadania e na qualidade de vida de mulheres no mundo todo, limitando seu pleno desenvolvimento enquanto sujeitos humanos constituintes e da sociedade.

Todavia, essa violência, que subjulga mulheres e submete-as a agressões de qualquer espécie não é prerrogativa conferida pelo Direito natural aos homens e não pode ser admitida em um Estado Democrático de Direito. Principalmente num Estado que tenha ratificado a Convenção Interamericana para Prevenir, Punir e Erradicar a Violência contra a Mulher, como é o caso do Brasil.

Referida convenção constitui importante ferramenta de promoção da emancipação das mulheres, principalmente porque estabelece como condição indispensável para o desenvolvimento individual da mulher e para sua plena e igualitária participação em todas as esferas da vida, a eliminação da violência contra ela. Assim, ao afirmar que a violência contra a mulher é uma violação dos direitos humanos e das liberdades fundamentais, bem como um limitador à observância, gozo e exercício de tais direitos e liberdades, a Convenção constitui importante ferramenta de promoção da emancipação das mulheres.

Por meio dos mecanismos de proteção estabelecidos pela Convenção, foi possível, por exemplo, a denúncia à Comissão Interamericana de Direitos Humanos do caso de violência doméstica e negligência estatal ocorrido com a senhora Maria da Penha Maia Fernandes. Referida denúncia, levou à instauração do caso de número 12.051 face ao Estado Brasileiro.

Em 04 de abril de 2001, 18 anos após a prática dos crimes, e ante a ausência de resposta do Estado Brasileiro, a Comissão, em decisão emblemática condenou o país por negligência e omissão em relação à violência doméstica e tornou público o relatório 54/01 incluindo-o no Relatório Anual à Assembleia Geral da Organização dos Estados Americanos. Nessa oportunidade, a Comissão reiterou suas recomendações ao Brasil, sendo que uma das mais relevantes para a sociedade brasileira foi que o país prosseguisse e intensificasse o processo de reforma que evite a tolerância estatal e o tratamento discriminatório com respeito à violência doméstica contra mulheres no Brasil.

Isso foi essencial para a proposição, no início de 2004, do Decreto 5.030, o qual instituiu um Grupo de Trabalho Interministerial, que elaborou, com a participação da sociedade civil e do Governo, uma proposta de medida legislativa e outros instrumentos 
visando coibir a violência doméstica contra a mulher. Referido grupo elaborou uma proposta que foi encaminhada ao Congresso Nacional no final do ano de 2004, que resultou na promulgação da Lei 11.340, em 07 de agosto de 2006, apelidada "Lei Maria da Penha", criando novos tipos penais, arranjos institucionais e políticas públicas no campo dos direitos da mulher.

Além de estar em perfeita sintonia com Convenção Interamericana para Prevenir, Punir e Erradicar a Violência contra a Mulher (Convenção de Belém de Pará, OEA, 1994), co a Convenção sobre a Eliminação de Todas as Formas de Discriminação contra as Mulheres (CEDAW, ONU, de 1979) e com a Constituição Federal (Brasil, 1988) (PASINATO, 2010) a lei Maria da Penha ainda introduziu inúmeras as inovações, principalmente a harmonização com a Convenção Interamericana para prevenir, punir e erradicar a Violência contra a mulher e fez com que conflitos que envolvam violência contra a mulher não possam ser considerados de "menor potencial ofensivo".

Acima de tudo, apesar do entendimento de alguns juristas brasileiros, a promulgação da Lei Maria da Penha atendeu à necessidade constitucional da existência de leis diferenciadas para desigualar as desigualdades físicas e materiais existentes no Brasil. Já que a Constituição prevê discriminações positivas para que, por meio de um tratamento desigual, se busque igualar aquilo que sempre foi desigual. Assim, como dito anteriormente, “inconstitucional não é a Lei Maria da Penha, mas a ausência dela”.

Finalmente, o que se pode perceber é que o maior problemas enfrentado na atualidade diz respeito à efetivação da lei, que não teve uma aceitarão consensual, tornando-se objeto tanto de controlarias jurídicas em torno de sua constitucionalidade como de críticas de profissionais e pesquisadora na área dos direitos da mulher, devido ao seu caráter punitivo ou à sua eficácia prática na resolução dos conflitos violentos. 


\section{REFERÊNCIAS}

AGENDE, Ações em Gênero Cidadania e Desenvolvimento. 10 anos da adoção da Convenção Interamericana para Prevenir, Punir e Erradicar a Violência contra a Mulher, Convenção de Belém do Pará . Brasília: AGENDE, 2004. Disponível em:< http:// artemis.org.br/wp-content/uploads/2013/11/revista-Convencao-Belem-do-Para.pdf $>$ Aceeso em: $21 / 09 / 2015$.

COMISSÃO INTERAMERICANA DE DIREITOS HUMANOS- OEA. Convenção interamericana para prevenir, punir e erradicar a violência contra a mulher, "Convenção de Belém do Pará". 1994. Disponível em: <http://www.cidh.org/Basicos/Portugues/ m.Belem.do.Para.htm> Acesso em 18/09/2015.

COMISSÃO INTERMERICANA DE DIREITOS HUMANOS - OEA. Relatório $n^{o}$ 54/01, caso 12.051, Maria da Penha Fernandes v. Brasil, 16/04/2001. Disponível em: <https:// www.cidh.oas.org/annualrep/2000port/12051.htm> Acesso em: 14/09/2015.

MACIEL, Débora Alves. Ação coletiva, mobilização do direito e instituições políticas: o caso da campanha da Lei Maria da Penha. Revista brasileira de ciências sociais. Vol. 26. № 77. 2011.

PASINATO, WÂNIA. Lei Maria da Penha: Novas abordagens sobre velhas propostas. Onde avançamos? Civita- Revista de Ciências Sociais. v. 10. No 10. Porto Alegre: 2010. Pp. 216-232.

PIOVESAN, Flávia e PIMENTEL, Sílvia. A Lei Maria da Penha na perspectiva da responsabilidade internacional do Brasil. In: CAMPOS, Carmem Hein de. Lei Maria da Penha comentada em uma perspectiva jurídico-feminista. Rio de Janeiro: Lumen Juris, 2011. Pp. 101 a 116.

PIOVESAN, Flávia e PIMENTEL, Sílvia. Lei Maria da Penha: inconstitucional não é a lei, mas a ausência dela. Carta Maior, 2007. Disponível em: < http://cartamaior.com.br/?/ Opiniao/Lei-Maria-da-Penha-inconstitucional-nao-e-a-lei-mas-a-ausencia-dela/21984> Acesso em: 17/09/2015.

PROGRAMA DAS NAÇÕES UNIDAS PARA O DESENVOLVIMENTO. Relatório de desenvolvimento Humano 2014. Disponível em: < http://www.pnud.org.br/arquivos/ RDH2014.pdf> Acesso em: 22/09/2015.

REVISTA FÓRUM. "Não estupro você porque não merece", diz Bolsonaro a Maria do Rosário. 2014. DISPONÍVEL EM: <http://www.revistaforum.com.br/2014/12/09/nao-estuprovoce-porque-nao-merece-diz-bolsonaro-maria-rosario/> Acesso em: 04/07/2015.

SANTOS, Cecília Macdowell. Da delegacia da mulher à Lei Maria da Penha: absorção/ tradução de demandas feministas pelo Estado. Revista crítica de ciências sociais - 89, 2010. Pp. 153 a 170.

STRECK, Lênio Luiz. Lei Maria da Penha no contexto do Estado Constitucional: desigualando a desigualdade histórica. In: CAMPOS, Carmem Hein de. Lei Maria da Penha comentada em uma perspectiva jurídico-feminista. Rio de Janeiro: Lumen Juris, 2011. pp. 93 a 100. 